\title{
Solar Energy System for Brunei Residence
}

\author{
Mohammad Yeakub Ali, Ahmad Syahmi Rahim and Seri Rahayu Ya'akub
}

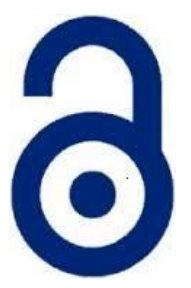

\author{
Received: 17 March 2021 \\ Accepted: 24 July 2021 \\ Published: 01 October 2021 \\ Publisher: Deer Hill Publications \\ (c) 2021 The Author(s) \\ Creative Commons: CC BY 4.0
}

\begin{abstract}
Brunei Darussalam is a country that receives high amounts of solar irradiation annually as it is located near the equator. With the abundance of oil \& natural gas resources, the country has one of the cheapest electricity costs in the world. This would in turn make solar power underutilized. The purpose of this project is to design a solar system for Brunei's medium sized residence to meet the daily energy demands. A comprehensive analysis was conducted on the solar photovoltaic system for determining the optimum sized parts and components. The design process was divided into detailed sections so that the values are calculated using PVSyst simulation software. The simulation also predicted the specific energy production, performance evaluation, and the losses. Cost analysis was also conducted to find the efficiency and the feasibility of the system. The designed solar energy system has a capacity of $60 \mathrm{kWp}$, producing $75 \mathrm{MWh}$ of usable energy annually. This system uses $66 \%$ of the energy available from the sun to generate electricity which covers the electrical demand of Brunei's residences.
\end{abstract}

Keywords: Solar energy, home electrification, off-grid solar electrification, PVSyst, Brunei Darussalam

\section{INTRODUCTION}

Brunei Darussalam (Abode of Peace), a small wealthy nation with about 430000 population, is located on the north coast of the Borneo Island in Southeast Asia surrounded by the South China Sea and Malaysian state of Sarawak. It has developed wealth from extensive petroleum and natural gas fields and is classified as a developed country. The economy of Brunei is small and wealthy, and is a mixture of foreign and domestic entrepreneurship, government regulation and welfare measures, and of village traditions. The government provides free education, excellent health care and pensions. The country relies on its fossil fuel produce to generate almost all the electrical energy to meet the energy demands. There is only one solar power plant in Brunei named Tenaga Suria Brunei that has a nominal capacity of around 1.2 kWp which generates an average total of approximately $1.3 \mathrm{GWh}$ of electricity per year (Ismail, 2015). Although Brunei has its own solar farm, it however, only generates at most $2 \mathrm{GWh}$ annually which is only $0.05 \%$ of the country's annual electricity generation (International Energy Agency, 2016). Brunei still aims to increase the use of renewable energy as source for power generation to 10\% by 2035 (Energy Department Brunei Darussalam, 2014). Brunei government subsidizes lot of consumables including energy. As a result, electricity cost in Brunei is one of the lowest in world where the tariff system in the country starts with B $\$ 0.01$ (USD 0.0075) per kWh for the first $600 \mathrm{kWh}$. Price per kWh increases for every increase in the tier (Table 1).

Located in the tropical region about 4 degrees north of the equator, the country experiences high amount of solar radiation all year round. With the amount of solar radiation, Brunei can take the upper hand to meet the electrical demand of its residences from solar sources alone. Taking advantage of this available abundance of solar resource can lessen the reliance on oil and gas and thus providing the country with clean energy.

The solar irradiance will not be that same across the surface of the earth as it varies differently between different region and with the diurnal cycle. The surface incident of electromagnetic energy per unit time on a unit area is called "solar irradiance" or often been referred to as "flux" (Stickler, 2016). The total solar irradiance that hits the earth's horizontal surface is the Global Horizontal Irradiance (GHI) (Vashishtha, 2012). Areas that are most favourable are in the subtropical regions where the value of the $\mathrm{GHI}$ can go up to $2618 \mathrm{kWh} / \mathrm{m}^{2}$, while part of northern Europe can be up to $824 \mathrm{kWh} / \mathrm{m}^{2}$ at most with much lower value during the winter.

Ali, M. Y.凶, Rahim, A. S. and Ya’akub, S. R.

Mechanical Engineering Programme Area

Faculty of Engineering, Universiti Teknologi Brunei

Tungku Highway, Gadong BE1410

Brunei Darussalam

E-mail: yeakub.ali@utb.edu.bn

Reference: Ali et al. (2021). Solar Energy System for Brunei Residence. International Journal of Engineering Materials and Manufacture, 6(4), 312-318. 
In many Southeast Asian regions, the sun radiates often, and it radiates intensively. However, this source is still used to different extent across different region. While China and India are already underway with much larger projects, the Southeast Asian potential is still largely untouched (Jacob, Billen, \& Bianchi, 2019). By 2025, the electricity demand is predicted to increase by $50 \%$ in the region. Thus, the organisation of ASEAN has decided to an objective where the region will use renewable sources for $23 \%$ of its primary energy to meet the demands.

\subsection{Problem Statement}

Combining those two factors together, Brunei's oil and gas produce is the primary source of generating energy while only $0.05 \%$ coming from solar PV. This shows that solar energy is not a popular way to generate their electricity to power up residences. With the high amount of solar irradiance Brunei receives, solar power is being underutilize. Since solar energy is not that popular in Brunei, there are limited studies that focuses on designing an off-grid solar energy system for Brunei's residences. This project might not have any immediate impact as the country still enjoy one of the lowest rates of electricity. Unfortunately, this luxury might disappear in the future. When the time comes, the country would want search for the best alternative to obtain cheap electricity, then this project will have its significance.

\subsection{Objectives}

The aim of this project is to design an off-grid solar system for Brunei residences with moderate electricity demand. There are specific objectives that should be attained in order to achieve the objective of this project:

- To estimate daily electrical load for residences within Lambak Area.

- To introduce a basic off-grid solar system layout and configuration.

- To select system components and carry out cost analysis.

- To simulate the model system using PVSyst software.

- To evaluate the performance for the designed system.

This project focuses on the design and simulation of a solar photovoltaic system fit to meet the electrical demand of Brunei residences specifically in a selected location named Lambak. Chapters are divided as follows.

A brief literature review in chapter 2 analyses the different types of energy sources, both renewable and nonrenewable, that is available worldwide. This chapter does put an emphasis more towards solar energy as its technologies and components are also reviewed.

Methods of research to design the system is outlined and explained in Chapter 3. This chapter shows the different steps to obtain variables that will help in the making of the system configurations.

Results from both simulation and calculations are portrayed and discussed in Chapter 4 where the basic design of the solar system layout and configurations are introduced. In this chapter, PVSyst software is used to simulate the effectiveness of the proposed design.

Conclusions from the project will be summarized in Chapter 5 where recommendations and suggestions are given to further improve the project or its related field in the future.

\section{SOLAR PHOTOVOLTAIC SYSTEMS}

Solar Photovoltaic System is a system where the process of converting solar radiation to electrical energy occurs. The systems are classified into two namely On-Grid, and Off- Grid solar photovoltaic systems.

On-Grid photovoltaic systems are designed specifically to operate with the national electrical grid connected to the system. This system is made to supply electricity for the AC electrical loads. When there is excessive amount of energy generated, the excess energy will be returned into the grid (Alkhadi \& Dulaimi, 2018).

A system where there is no connection to the national electrical power grid is classified as an off-grid solar photovoltaic system. This system comprises of the photovoltaic module, solar charge controller, batteries, inverters, and loads (Figure 1) (Alkhadi \& Dulaimi, 2018).

This system uses the solar panels to provide electrical power during the day and use electricity stored in batteries during the night. The batteries will then be recharged during the day to store electrical energy where the light from the sun is available.

For a small-scale stand-alone system, it does not have to be attached on the roof top of the houses or buildings as it can be portable. This will provide more reliable and free electrical power anywhere. It also provides back up power supply when there is no solar energy absorbed by the solar panel. 


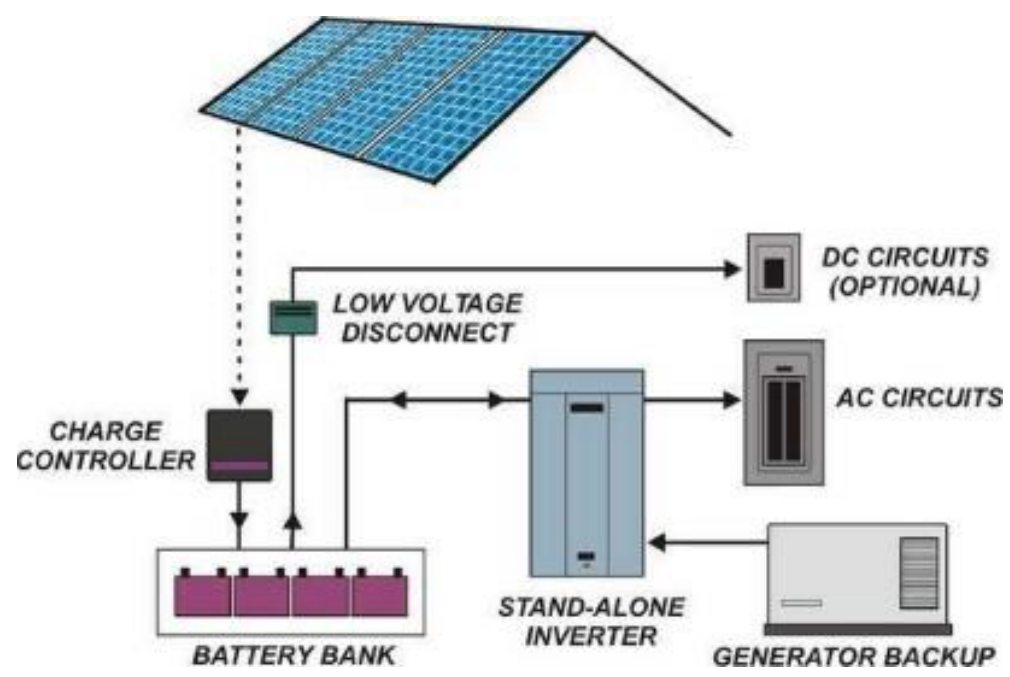

Figure 1: Schematic Diagram of an Off-Grid System (Alkhadi \& Dulaimi, 2018)

\section{SOLAR SYSTEM DESICNS}

Numerous studies have been published with regards to the different designs of solar systems in different countries. These studies were mostly done in countries that are in the subtropical climate such as Bangladesh, Egypt, Iraq, Jordan, and Nigeria, where the potential of solar energy is the greatest.

When comparing these studies' research methods, they are somewhat similar where the estimation of load being the first parameter to be found. Another parameter comes after load estimation is determining the tilt angle with respect to their geographical location. Then comes the selection of their area's system voltage, followed by the selection of the photovoltaic system components which begins with the photovoltaic module. These pre-determined components help to design the system with controlled variables.

Studies on the designing of the solar energy system resulted in different configurations even if some studies were carried out in the same country. The reason being is that the criterial components are different. Not only that but some countries are big thus determining the tilt angle might have been slightly different. Some studies include the material and dimensions of the wire used in the system to ensure minimal power loss. Some studies also include the calculation of payback period of the system to show the worth of implementing solar photovoltaic system for residences.

\subsection{Daily Load Estimation and Sun Hours}

In order to know the electrical demand of Brunei's residences, load estimation survey is to be conducted. This survey includes the estimated daily energy demand in Watt-hour of all the appliances used in a residence. The average total energy consumption will be used to figure out the sizing and rating of each component.

The amount of sunlight that photovoltaic modules receive is also important to consider when designing a solar energy system. Electrical energy a photovoltaic module can be more accurately represented during peak sun hours. Peak sun hours are the hour when sunlight is at its most intense where the usual average may lie closer to 3 or 4 hours. The average total of peak sun hours will also be used to figure out the sizing and rating of each component.

System sizing is basically the process of calculating and evaluating the suitable voltage and current for each of the photovoltaic system components. The evaluation has to be done in order to meet the demand of the daily consumption of electricity in a residence.

This chapter focuses on the design of the solar energy system for the residences of Brunei Darussalam. Also, included in this chapter is the results obtained from the load estimation surveys, the findings of necessary parameters, the calculation results of the designing processes and the simulation results of design performance.

There are 40 survey-interviews that were successfully conducted on different households of Kampong Lambak and its surrounding areas where each household provided different load profile estimates. The total power used varies from $10.270 \mathrm{~kW}$ to $38.801 \mathrm{~kW}$. Whereas the energy consumption varies from $58.342 \mathrm{~kW} /$ day to 362.590 kWh/day (Figure 2). Load profile of the appliances for selected households are shown in 'Appendix A'.

The sun hours that Brunei received annually is a minimum of 4 hours per day. This means that the solar insolation in which this country would receive 4 hours of the sun at its peak giving out the maximum irradiance of around 1 $\mathrm{kWm} 2$. Although Brunei is located near the equator where the solar radiation is high all year round, its sun hours are not as much as those of the subtropics or desert areas (Figure 3). 


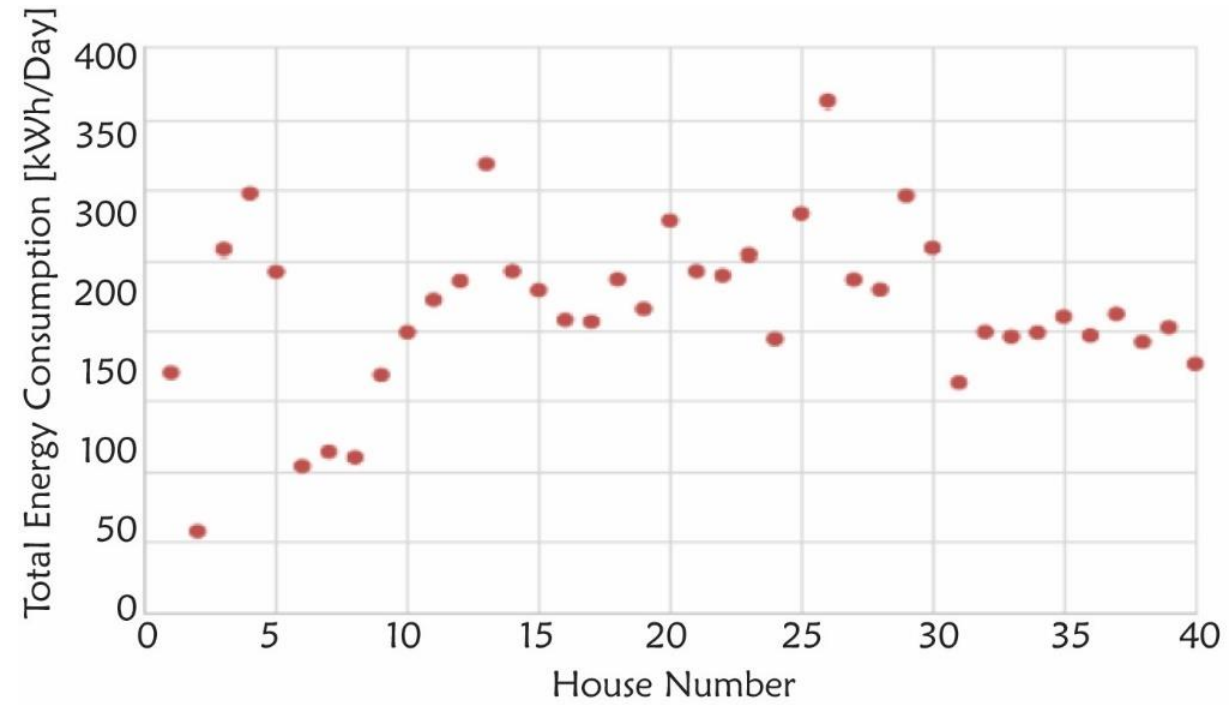

Figure 2: Graph of total daily energy consumption for each household surveyed

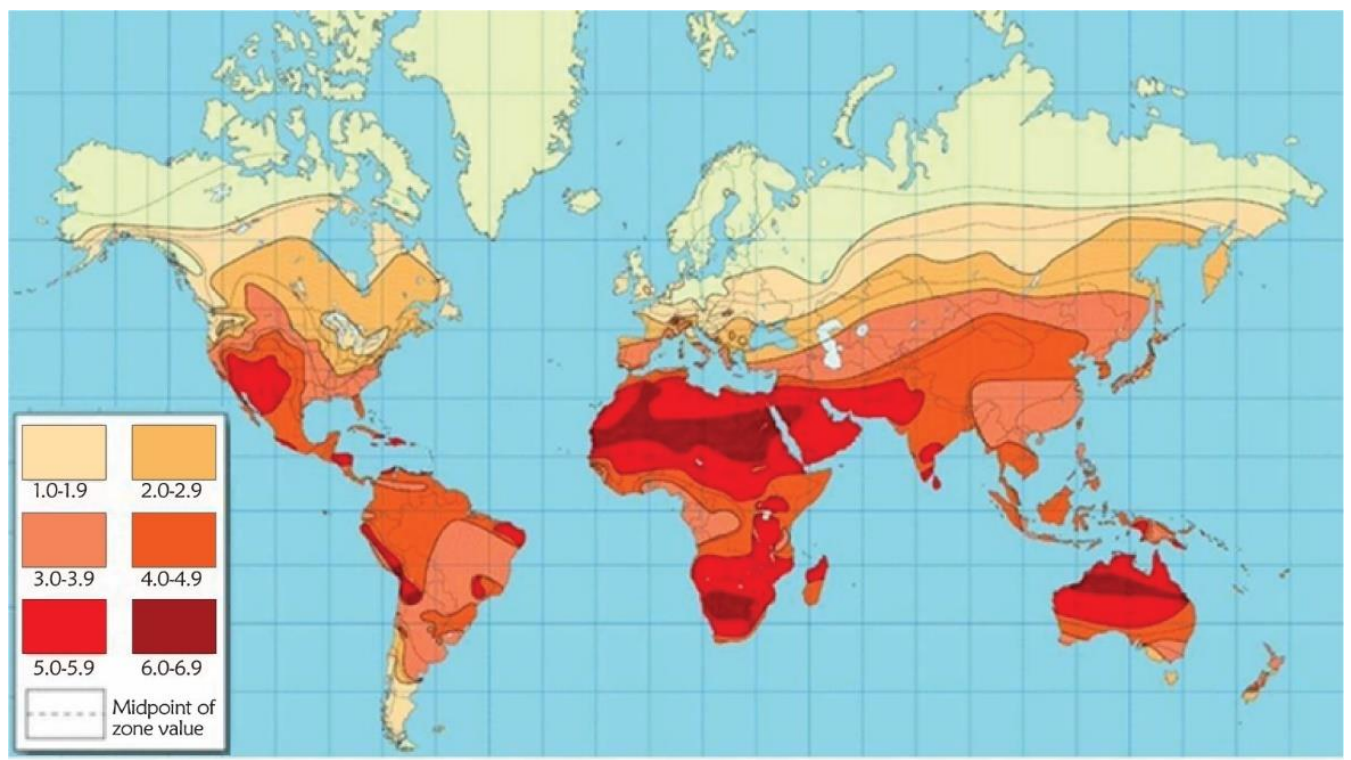

Figure 3: Amount of Sun hours received each day (altE, 2020)

\section{PVSYST SOFTWARE SIMULATION}

The designed photovoltaic system has undergone simulation using the PVSyst Software and in this section, results from the simulation of the designed system will be analysed. From the simulation, the energy produced by the system, specific production value, performance ratio and system losses were acquired. The obtained results will be analysed for the performance evaluation of the designed photovoltaic system. Full report obtained from the PVSyst Software Simulation is shown in 'Appendix C'.

From the obtained main simulation results, there are three main parameters that has been evaluated. The first parameter being the total amount of energy that was generated by the system on an annual basis. The energy produced by the designed photovoltaic system is $90.87 \mathrm{MWh} /$ year. The second parameter is the specific production of energy by the designed system on an annual basis for each installed kWp which is $1456 \mathrm{kWh} / \mathrm{kWp} /$ year. The third main parameter that has been evaluated by the software is the average yearly performance ratio of $66.05 \%$.

PVSyst software did not compute the system efficiency. Therefore, the evaluation of system efficiency must be done manually. Since the annual value of the energy that is directly supplied to the user is known, the average monthly value for the energy that is supplied to the user is $6257.75 \mathrm{kWh}$. From the full report in 'Appendix C', under the PV Array Characteristics, the collector area can be acquired thus enabling the calculation of the efficiency of the designed system. The formula of calculating system efficiency is provided by PVSyst as shown in Equation 1 (PVSyst, n.d.) 


$$
\text { System Efficiency }=\frac{\text { Average Monthly } E_{\text {User }}}{\text { Collector Area }}
$$

Various losses in the designed photovoltaic system are represented in the arrow lost diagram that was obtained from PVSyst software simulation (Figure 4). The diagram helps to analyse the various losses that are to be faced when installing the system. From the diagram, horizontal global irradiation is $1816 \mathrm{kWh} / \mathrm{m} 2$. However, the effective irradiation on the collector is $1766 \mathrm{kWh} / \mathrm{m} 2$. Just from irradiance level itself, a loss of $3.1 \%$ of initial energy already occurs. When the effective irradiation falls on the surface of the photovoltaic module, electrical energy is produced, thus undergoing the photovoltaic conversion phase. After undergoing the photovoltaic conversion phase, the array nominal energy at standard testing condition is $110.3 \mathrm{MWh}$. At standard testing conditions, the efficiency of the photovoltaic array is $17.86 \%$. The effective energy at the output of the array is $92.5 \mathrm{MWh}$. There are various losses in between where $0.6 \%$ are losses due to irradiance level, $11.2 \%$ are losses due to the temperature, $2.5 \%$ losses through unused energy due to full battery, and mismatch losses and ohmic wiring losses at $1.1 \%$ and $2.3 \%$ respectively. A total of $17 \%$ of losses occurs in this stage. From the photovoltaic array, the energy will pass through the charge controller and inverter. At this stage, the energy reduces to $88.5 \mathrm{MWh}$. A total of $4.4 \%$ losses occurred within the charge controllers and inverters. There are further losses when it reaches the energy supplied to the user stage, which by now the energy reduces to $75.1 \mathrm{MWh}$. During energy storage, a further $17.9 \%$ losses occurred in the process of battery storage.

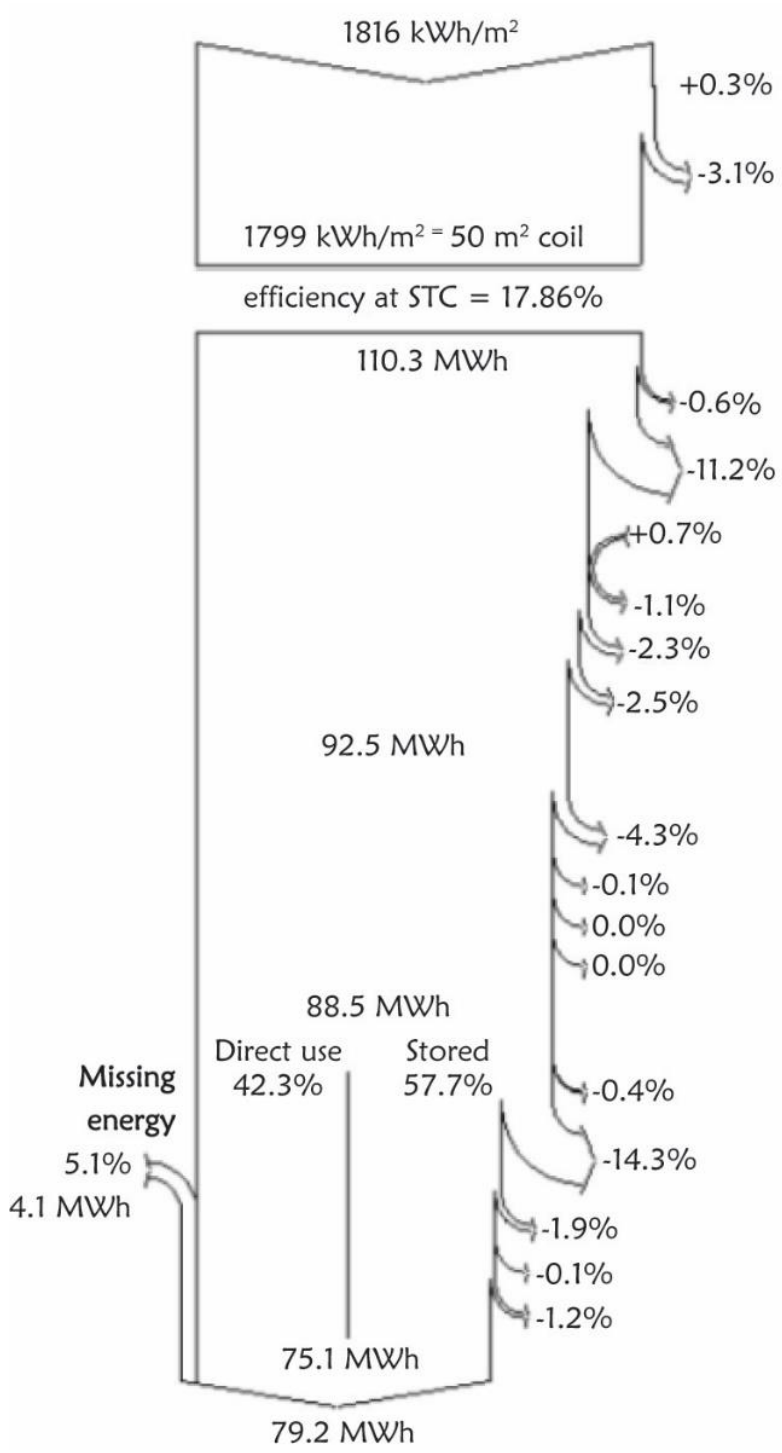

Horizontal global irradiation Global incident in coil. plane

IAM factor on global

Effective irradiation on collectors

PV conversion

Array nominal energy (at STC effic.)

PV loss due to irradiance level

PV loss due to temperature

Module quality loss

Mismatch loss, modules and strings

Ohmic wiring loss

Unused energy (battery full)

Effective energy at the output of the array

Converter Loss during operation (efficiency)

Converter Loss due to power threshold

Converter Loss over nominal conv. voltage

Converter Loss due to voltage threshold

Converter losses (effic, overload)

Battery storage

Battery Stored Energy balance

Battery efficency loss

Charge/Disch. Current Efficiency Los

Gassing Current (electrolyte dissociation)

Battery Self-discharge Current

Energy supplied to the user

Energy need of the user (Load)

Figure 4: Arrow loss diagram for the designed photovoltaic system 


\section{COST ANALYSIS}

Since the photovoltaic system has been designed, cost analysis can be carried out. Cost analysis can give strong evidence on the performance of the designed system whether it is efficient or not. Furthermore, this analysis can determine the feasibility of the system if it were to be installed. The cost breakdown of the selected component of the system and its designed quantity has been tabulated in Table 1 With that high total cost of the system, it is very possible that bank loan is needed to install the designed system.

Table 1: Cost breakdown of system components

\begin{tabular}{|c|c|c|c|c|}
\hline Items & Manufacturer & Rating & Qty & Cost (USD) \\
\hline $\begin{array}{c}\text { Photovoltaic } \\
\text { Modules }\end{array}$ & Talesun & $300 \mathrm{~W}$ & 208 & 15600 \\
\hline $\begin{array}{l}\text { Solar Charge } \\
\text { Controller }\end{array}$ & Bluesun & $\begin{array}{c}48 \mathrm{~V} \\
140 \mathrm{~A} \max \end{array}$ & 10 & 1280 \\
\hline $\begin{array}{c}\text { Deep-Cycle } \\
\text { Batteries }\end{array}$ & Deka & $253 \mathrm{Ah}$ & 308 & 64680 \\
\hline Inverters & Jinan Deming & $40 \mathrm{~kW}$ & 1 & 3049 \\
\hline $\begin{array}{l}\text { Mounting, Cabling } \\
\text { and Connector }\end{array}$ & Generic & - & - & 500 \\
\hline \multicolumn{4}{|c|}{ Estimated Shipping Cost by Sea } & 4000 \\
\hline \multicolumn{4}{|c|}{ Total Cost of the system } & 85109 \\
\hline \multicolumn{4}{|c|}{ Total Cost System after 10 years of $4.5 \%$ p.a. Financing } & 123408.05 \\
\hline
\end{tabular}

\section{CONCLUSIONS \& RECOMMENDATIONS}

The aim of this project was to design an off-grid solar system for Brunei residences to meet the moderate electricity demand. The objective was achieved by estimating the daily electrical needs of residences around Lambak area. PVSyst simulation software is used in this project to verify the efficiency and feasibility of the design. This research showed:

1. A multi-staged criterion was conducted when designing this solar photovoltaic system. This gives the best optimization to the selection of ratings for each of the main component as well as its arrangement. The designed solar energy system did meet its energy demand both during the day and night. Furthermore, the system can provide energy to meet the load demand on a maximum of 3 days without solar input.

2. The results from the software simulation did verify the efficiency and the feasibility of the system design as it converts $66.1 \%$ of the sun's energy into electricity. Furthermore, the specific energy cost of the system is USD 0.08 per kWh and has a payback period of 21.7 years further proves efficiency and the feasibility of the designed system. The low cost per kWh shows that the solar photovoltaic sources are indeed a good alternative for electricity generation in this country.

3. Finally, this project provides a base and structure for the evaluation of the design solution. The evaluation is not only restricted to Lambak and its surrounding areas, but also in other parts of the country since the sun irradiation is high all year round. This project may not be as important as it is now, but when the country is considering renewable energy sources for cheap energy, then this project will have its significance. Conclusions \& Recommendations

4. The survey that was carried out to determine the total power usage and daily load consumption is not accurate, thus resulting of an overestimated value for system sizing. This, in turn, would make the current evaluated cost to be higher than it should. Therefore, making the payback period longer and the specific cost per kWh higher.

5. This project can be further improved by conducting a more in-depth survey to accurately measure the energy usage of a household to obtain the weekly power usage so that more accurate evaluation can be done. Further improvements can be made by including the wires used to connect each component for system sizing and performance simulation so that it gives more accurate results that can be applied in real life.

6. The survey that was carried out to determine the total power usage and daily load consumption is not accurate, thus resulting of an overestimated value for system sizing. This, in turn, would make the current 
evaluated cost to be higher than it should. Therefore, making the payback period longer and the specific cost per kWh higher.

7. This project can be further improved by conducting a more in-depth survey to accurately measure the energy usage of a household to obtain the weekly power usage so that more accurate evaluation can be done. Further improvements can be made by including the wires used to connect each component for system sizing and performance simulation so that it gives more accurate results that can be applied in real life.

\section{REFERENCE}

1. H. Ismail, “Tenaga Suria Brunei - Brunei's very own solar farm!” Solar Brunei, 2015. [Online]. Available: https://www.solarbrunei.com/blogs/news/76917508-tenaga-suria-brunei-bruneis-very-own-solar-farm. [Accessed 2019].

2. “Electricity Information 2016," International Energy Agency, 2016. [Online]. Available: https://www.iea.org/statistics/?country=BRUNEI\&year=2016\&category=Electricity\&indicator =SolarGen\&mo de $=$ table\&dataTable $=$ ELECTRICITYANDHEAT. [Accessed 2019].

3. Energy Department Brunei Darussalam, Energy White Paper, Bandar Seri Begawan, Brunei Darussalam: Energy Department, Prime Minister's Office Brunei Darussalam, 2014.

4. G. Stickler, "Educational Brief - Solar Radiation and the Earth System," National Aeronautics and Space Administration, $2016 . \quad$ [Online]. Available: https://web.archive.org/web/20161229182712/http://education.gsfc.nasa.gov/experimental/July61999siteupda te/inv99Project.Site/Pages/science-briefs/ed-stickler/ed-irradiance.html. [Accessed 2019].

5. S. Vashishtha, "Differentiate Between the DNI, DHI and GHI," First Green Consulting, 2012. [Online] Available: https://firstgreenconsulting.wordpress.com/2012/04/26/differentiate-between-the-dni-dhi-and-ghi/. [Accessed 2019].

6. J. Jacob, D. Billen, and G. Bianchi, Solar Power: Shining Prospects in Southeast Asia and India, Munich, Germany: Roland Berger $\mathrm{GmbH}, 2019$.

A. Alkhalidi, and N. Dulaimi, "Design of an Off-Grid Solar PV System for a

7. rural shelter," 2018. doi:10.13140/RG.2.2.24352.07689

8. "Solar Insolation Map - World," altE, 2020. [Online]. Available: [Accessed 2020].

9. "Simulation $\quad$ variables: Standalone PVSyst.. Available: https://www.pvsyst.com/help/simulation_variables_standalone.htm. [Accessed: 10 July 2020]. 